\title{
A Model-Based Cost-Minimization Analysis as a Decision Tool in Obstetric Care in Helgeland, Northern Norway
}

\author{
Halvard Angelsen ${ }^{1}$, Jan Norum ${ }^{2,3}$, Villy Angelsen ${ }^{4}$, Fred A. Mürer ${ }^{5} \&$ Randi Erlandsen ${ }^{5}$. \\ ${ }^{1}$ Department of Radiology, University Hospital of North Norway, Tromsø, Norway \\ ${ }^{2}$ Institute of Clinical Medicine, Faculty of Health Sciences, UiT - The Arctic University of Norway, Tromsø \\ ${ }^{3}$ Northern Norway Regional Health Authority trust, Bodø, Norway \\ ${ }^{4}$ Vestvågøy Community, Leknes, Norway \\ ${ }^{5}$ Helgeland hospital, Mo i Rana \\ Correspondence: Jan Norum, Northern Norway Regional Health Authority trust, N-8038 Bodø, Norway. Tel: \\ 47-95-404-205. E-mail: jan.norum@helse-nord.no
}

Received: February 19, 2016 Accepted: April 18, 2016 Online Published: May 19, 2016

doi:10.5539/gjhs.v9n1p191 URL: http://dx.doi.org/10.5539/gjhs.v9n1p191

\begin{abstract}
Background: Quality of care is of utmost importance in maternity care. Today, we base the choice of institution on risk factors. Recently, a Norwegian national plan introduced new guidelines concerning quality and staffing. Consequently, the hospital trusts had to increase the number of obstetricians and midwives and handle raised costs. One way to meet such challenges is to reduce the number of delivery units.
\end{abstract}

Objectives: We aimed to clarify the costs and benefits of two alternative strategies in obstetric care in Helgeland hospital trust using a model-based cost-minimization analysis (CMA).

Methods: The consequences, in terms of cost/savings and mothers' time of travelling, by closing two midwife-administered maternity units (MAMUs) and keeping the two departments of obstetrics (DOGs) running was analyzed. We implemented data from the Helgeland hospital trust and the Medical Birth Registry of Norway (MBRN) and the selected period was 2010-2012. The comparator was today's organization. Costs were converted into Euros at the rate of $€ 1=$ NOK 9.527.

Results: The model concluded the closing of two MAMUs created an annual net saving of $€ 584,346$. The mothers' mean time of travelling increased by 11 minutes and by 91 minutes for those directly affected by the closure. The organizational changes were concluded safe and of low risk with regard to quality of care. A sensitivity analysis revealed the number of midwives dismissed being the most important variable.

Conclusion: A model-based CMA may be a supportive tool when evaluating maternity care.

Keywords: obstetrics, economics, Norway

\section{Introduction}

Norway has a population of 5.2 million inhabitants. Northern Norway covers almost half of Norway's landmass, but has only $9.4 \%$ (480.740 inhabitants) of the population and people are scattered within an area of $112,946 \mathrm{~km}^{2}$. The northern region is located in the sub-Arctic and Arctic areas of Norway and has a rough climate. Strong and cold winds, ice and snow are common during winter. Whereas there are seasonable darkness, the summer has constant daylight due to the midnight sun. The scattered population and the climate challenges have called for a decentralized maternity care. However, during the last decades, the number of delivery units in Northern Norway has been steadily declining. Especially, the numbers of midwife-administered maternity units (MAMUs) have been reduced. More people have moved to the cities and improved infrastructure in terms of new or upgraded roads, tunnels, bridges and airports have called for changes in the health care in general. Today, there are 15 obstetric care institutions within the region and four of them are in the Helgeland region.

A new national plan for maternity care was recently launched (Ministry of Health and Care Services, 2009) and fully implemented in Northern Norway in March 2012. In this plan, safety, manning and quality were the main issues. Today, the obstetric care is available at three levels of care: Midwife-administered maternity units 
(MAMU), Departments of obstetrics and gynaecology (DOG) and Regional clinics of obstetrics and gynaecology (RCOG)). According to national guidelines (Norwegian Directorate of Health, 2010), the decision concerning level of care for each individual mother is generally carried out early during pregnancy. Possible occasions are the follow up visit in primary health care during the first trimester or at ultrasound screening at $18^{\text {th }}$ week of pregnancy.

In Norway, two-thirds gave birth to their children at regional clinics of obstetrics and gynaecology (RCOG) (Norwegian Institute of Public Health, 2014). They have a large capacity, an excellent emergency service and several medical specialities (gynaecologist, anaesthesiologist, and pediatrician) available on duty when needed. They do also have intensive care units for newborns.

The MAMUs do not have any gynaecologist on duty. They are located at minor hospitals and administered by a midwife. Due to women's choice and selection criteria, only $40 \%$ of the pregnant women next to MAMUs give birth to their children at these units (Northern Norway Regional Health Authority trust, 2011). Despite an annual decline in number of births, the MAMUs have to keep the necessary staffing day and night. According to upgraded guidelines, a midwife should be present constantly during the active stage of the labour. Fewer births and only a low risk population at the MAMUs may influence on these midwives' competence. Furthermore, the new guidelines recommended DOGs having four (instead of three) gynaecologists included in the duty shifts. The Helgeland hospital (HH) trust has two MAMUs and two DOGs and now faces a significant challenge with fewer births (less income to the hospital trust), new guidelines causing heavy manning costs (more midwives and gynaecologists) and risk of losing competence. In such a situation where budget and expenses must be balanced, a model-based cost-effectiveness analysis (CEA) may be an excellent tool.

\section{Material and Methods}

\subsection{The Helgeland Region and the Helgeland Hospital Trust}

Helgeland is the southern region of Northern Norway and covers an area of almost $18,000 \mathrm{~km}^{2}$. There are eighteen communities and the region has a population of 78,400 inhabitants and most of them $(54,000$ inhabitants) are situated in the city-municipalities (Rana, Vefsn, Alstahaug, Brønnøy) (Statistics Norway, 2014). The three hospitals (Sandnessjøen hospital, Mosjøen hospital, Rana hospital) in Helgeland are situated in the cities Sandnessjøen, Mosjøen and Mo i Rana, respectively. Locations are shown in Figure 1. The two MAMUs are located in Brønnøysund and Mosjøen. The two DOGs are situated in Sandnessjøen and Mo i Rana. Women in need of a RCOG service are transported to the Nordland hospital in Bodø. In exceptional cases, they may be transported to the University hospital of North Norway (UNN) in Tromsø or to St. Olav's hospital in Trondheim.

When in need of emergency transportation to a superior level of care, patients may access significant resources for transportation within the Helgeland region. There are two air-ambulance resources (one fixed wing (FW) and one rotor wing (RW)) located in Brønnøysund and similarly in Bodø. The FWs have a specialized nurse as a staff member. Employing the FW in Brønnøysund, a pregnant woman at the MAMU can be transport to the RCOG in Bodø within an hour. All ambulance helicopters (RW) have an anaesthesiologist as a member of the crew. 


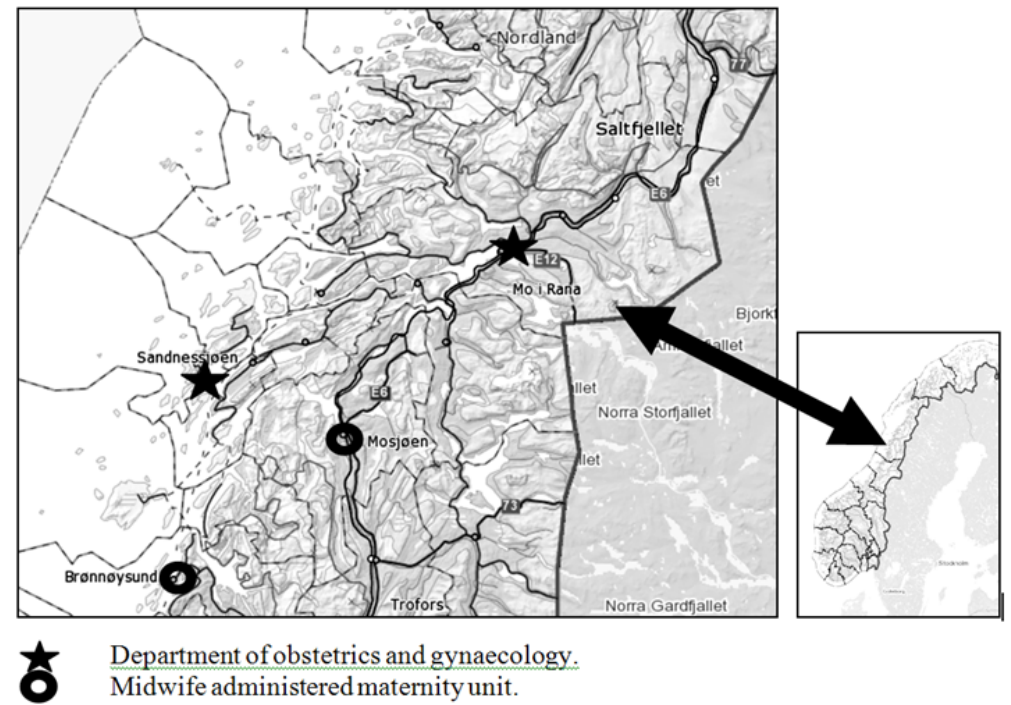

Figure 1. The figure shows the Helgeland region in northern Norway (www.kartverket.no).

Similarly, the 330-sqadron has a Sea King (RW) search and rescue (SAR) helicopter operating from Bodø. There are also three high speed (35 knots) ambulance boats located at Vega, Bjørn and Rødøy. Furthermore, the trust has 16 car ambulances.

During the last years, the region has experienced a significant upgrading of infrastructure. In late 2005, the 8.5 $\mathrm{km}$ tunnel through the Korgen mountain between Mosjøen and Mo i Rana was opened. Especially, during winter, the Korg mountain could be a serious challenge when patients needed to be transported from Mosjøen to Mo $\mathrm{i}$ Rana. In late 2014, the $10.7 \mathrm{~km}$ long Toven tunnel was finished and the time of travel between the hospitals in Sandnessjøen, Mosjøen and Mo i Rana was reduced by 15-35 minutes and the communication by ambulance could be more predictable and safe. The cost of the Korgen tunnel was $€ 47.2$ million and the Toven tunnel $€$ 153.2 million, respectively. When doing such investments, the society always look for possible savings in public sectors, in example the specialized health care service. The Helgeland hospital trust has staffed its delivery units by midwives and midwife assistants. An overview is shown in Table 2 .

Table 1. The staffing (according to 2013 figures) of the four delivery units at the Helgeland hospital trust

\begin{tabular}{lll}
\hline Location & Midwives & Midwife assistants \\
\hline Mo i Rana & 13 & 5 \\
Sandnessjøen & 11.6 & 3.2 \\
Mosjøen & 8 & - \\
Brønnøysund & 5 & - \\
\hline
\end{tabular}

\subsection{Today's Model and the Comparator}

Today, mothers are transported to the nearby delivery unit (MAMUs in Brønnøysund and Mosjøen, DOGs in Sandnessjøen and Mo i Rana), according to mothers' choice and national selection criteria (Norwegian Directorate of Health, 2010). The comparator was a new model with only two DOGs located at Sandnessjøen and Mo i Rana.

\subsection{Quality of Care}

We postulated that the obstetric care was of high quality. Furthermore, we argued that a centralisation of births by reducing the number of institutions (from four to two units) would not influence on quality of care. To support this hypothesis, we accessed data from the Medical Birth Registry of Norway (MBRN) (Norwegian Institute of Public Health, 2014) in March 2014. The following data were accessed: Births, newborns, born alive or dead, birth weight below $2.5 \mathrm{~kg}$ and Apgar score $<7$ five minutes after birth, forceps and vacuum assisted delivery, 
gestational diabetes mellitus (GDM), eclampsia, perineal rupture grade 3 (partial or total tear through the anal sphincter) or 4 (grade 3 with extension through the rectal mucosa) and caesarean section.

\subsection{Distance of Travelling}

The mothers address according to municipality was registered. We calculated all distances of travel from the centre of mother's municipality to the delivery unit employing the calculator of the Norwegian Automobile Association (NAA) (Norwegian Automobile Association, 2014). The centres of the municipalities were selected, as the primary health care services are located there. General practitioners (GPs) working at these centres make the decisions on further transportation. We calculated the distance according to two alternatives: (A) Today's structure (2 MAMUs \& 2 DOGs). (B) Only 2 DOGs (Sandnessjøen and Mo i Rana) and implemented the effect of the new Toven tunnel.

According to national guidelines (Ministry of Health and Care Services, 2009, Norwegian Directorate of Health, 2010), when a mother have to travel a distance of more than 1.5 hours to the delivery unit, it must be considered whether she is in need of an accompanying midwife during the journey. Every case must be considered individually.

\subsection{Exclusion and Inclusion Criteria}

In this study, we included women who gave birth to their children at the Helgeland hospital trust during the three years period 2010-2012. When calculating distance of travelling, we excluded women who did not have any address in the Helgeland region (in example on holiday in the region). They constituted five women annually.

\subsection{Units of Cost and Savings and Calculations}

Costs of travelling: According to information from the trust, most women travel by their family car to the delivery units. To clarify these costs, we used the 2013 national public tariff (travelling by car, $€ 0.4 / \mathrm{km}$ ). We included the value of an accompanying person in the car $(€ 0.1 / \mathrm{km})$ as the pregnant woman never travels alone. Accommodation costs were not included as family visits may be performed as day-trips in both models. Furthermore, we considered that any costs due to father's leave from work would be equal in both models. Consequently, this cost was not included in the model.

Health care costs: Costs of birth, caesarean section and maternity stay were calculated according to the Diagnosis Related Group (DRG) system (Norwegian Directorate of Health, 2011) and the tariff of 2012 was used. Costs due to accompanying midwives during travelling (when needed) were based on the resources spent at the trust during the period 2010-2012. The midwife wages per hour ( $€$ 31.1) was multiplied with the time of travel from the centre of the municipality to the delivery unit. Based on agreements with the union, midwives were paid for a minimum of three hours per trip. In some cases, when the mothers lived in small distant municipalities on islands where they were in need of a ferry, the travelling time calculated by the NAA calculator could be insufficient. In these cases, we used ambulance boats in the model and adjusted the figures according to their cruising speed.

Health care savings: By closing the two MAMUs (Brønnøysund and Mosjøen), the need for midwives will be reduced and consequently human resources saved. We used the mean cost (including social costs as deposition for pension, sick leave, employer's tax etc.) per midwife employed at the trust $(€ 84,237.3)$.

\subsection{Statistics and Authorizations}

Microsoft Excel for Mac 2011 version 14.4.1 was used for the database and the calculations. Descriptive statistics and the Chi-square test was used for the comparison between subgroups. Significance was set to 5\%. The study was performed as a cost-minimum analysis (CMA) (Drummond et al., 2005). Consequently, all costs equal in the two alternatives were excluded from the analysis. We accessed anonymous and aggregated data from an open source (MBRN) and from the Department of Economics at the hospital trust and the comparison between models was based on descriptive statistics. Data from the MBRN was available on the Web free of cost and as we imported aggregated data, no ethical committee or Data Inspectorate approval was necessary. Consequently no approval from the Regional Committees for Medical and Health Research Ethics (REK) was necessary. Similarly, no approval from the Norwegian Social Science Data Services (NSD) was required. Costs were converted into Euros $(€)$ according to the exchange rates $(€ 1=9.5270$ NOK$)$ of the Central Bank of Norway (www.norges-bank.no) the $23^{\text {rd }}$ of December 2015.

\section{Results}

\subsection{Quality of Care}

The quality of care in the Helgeland hospital trust was similar or better than national figures. However, there were differences within the hospital trust. In example, the incidence of gestational diabetes mellitus (GDM) 
varied significantly between the two DOGs (Sandnessjøen and Mo i Rana) $(\mathrm{P}=0.02)$. Details are shown in Table 2.

Table 2. The table shows the quality figures of the four delivery units in Helgeland hospital trust compared with their total figures and national figures (2010-12)

\begin{tabular}{lllllllllll}
\hline Institution & Births & CS (\%) & $\begin{array}{l}\text { Vacuum } \\
(\%)\end{array}$ & & $\begin{array}{l}\text { Forceps } \\
(\%)\end{array}$ & $\begin{array}{l}\text { Apgar } \\
<7(\%)\end{array}$ & $\begin{array}{l}\mathrm{W}<2.5 \\
\mathrm{~kg}(\%)\end{array}$ & $\begin{array}{l}\text { Deaths/ } \\
1000\end{array}$ & $\begin{array}{l}\text { Perianal } \\
\text { ruptur } \\
\text { Grad } \\
(\%)\end{array}$ \\
\hline Mo i Rana & 1,126 & 14.9 & 9.2 & 0.2 & 1.9 & 1.6 & 2.7 & 1.9 & 0.0 & 11000 \\
Sandnessjøen & 797 & 15.7 & 7.1 & 0.3 & 1.9 & 2.5 & 6.3 & 1.4 & 1.3 & 25.3 \\
Mosjøen & 154 & 0.0 & 0.0 & 0.0 & 0.0 & 0.6 & 0.0 & 0.7 & 0.0 & 13.2 \\
Brønnøysund & 109 & 0.0 & 0.0 & 0.0 & 0.9 & 0.0 & 0.0 & 0.0 & 0.0 & 0.0 \\
Helgeland & 2,186 & 15.2 & 8.3 & 0.2 & 1.7 & 1.8 & 3.7 & 1.5 & 0.5 & 16.1 \\
Norway & 180,635 & 16.5 & 8.4 & 1.6 & 1.8 & 5.0 & 3.8 & 1.8 & 0.5 & 20.9 \\
\hline
\end{tabular}

$\mathrm{CS}=$ Caesarean section. $\mathrm{W}=$ Weight. $\mathrm{GDM}=$ Gestational diabetes mellitus.

The maximum number of births was observed in April and during summertime (June - September). The percentage of births in each quarter of the year was: 24.8\% (Jan.- Mar.), 25.7\% (Apr.- Jun.), 27.1\% (Jul.- Sep.) and $22.3 \%$ (Oct.- Dec.), respectively. This documented increased workload simultaneously with the staff's summer holiday (Jul.-Sep.).

\subsection{Health Economics}

Health care costs: Employing the DRG figures of 2012 (DRG 373-454 cases, DRG 372-114 cases, DRG 371-80 cases, DRG 370-31 cases, DRG 374-34 cases, DRG 375-12 cases, DRG 375O-5 cases), the total value of the obstetric care was calculated $€ 1,863,418$ per year.

Travelling costs: The new model increased the mean time of travelling by 91 minutes for those living in the neighbourhood of the MAMUs in Mosjøen and Brønnøysund. In total, the increased mean time of travelling per mother was 11 more minutes in the new model. The greatest impact was observed in Brønnøy municipality. The total extra cost of travelling was calculated $€ 6,365$. Details are shown in Table 3 .

Table 3. The table shows the cost of travelling in today's model (four delivery units) and in the new model (two delivery units) according to municipality in the Helgeland region

\begin{tabular}{lllllll}
\hline Municipality & Centre & $\begin{array}{l}\text { Travelling } \\
\text { time today } \\
(\mathrm{min} .)\end{array}$ & $\begin{array}{l}\text { Travelling time } \\
\text { new } \\
(\mathrm{min} .)\end{array}$ & Difference & $\begin{array}{l}\text { Births } \\
(2010-2012)\end{array}$ & $\begin{array}{l}\text { Costs } \\
(€ 0.5 / \mathrm{km})\end{array}$ \\
\hline Bindal & Terråk & 116 & 116 & 0 & 8 & 0 \\
Sømna & Vik & 33 & 186 & 153 & 6 & 0 \\
Brønnøy & Brønnøysund & 0 & 163 & 163 & 75 & 3,609 \\
Vega & Gladstad & 82 & 126 & 44 & 8 & 0 \\
Vevelstad & Vevelstad & 60 & 102 & 42 & 4 & 0 \\
Herøy & Silvalen & 64 & 64 & 0 & 14 & 0 \\
Alstadhaug & Sandnessjøen & 0 & 0 & 0 & 71 & 0 \\
Leirfjord & Leland & 18 & 18 & 0 & 18 & 0 \\
Vefsn & Mosjøen & 0 & 45 & 45 & 124 & 2,481 \\
Grane & Trofors & 35 & 74 & 39 & 12 & 110 \\
Hattfjelldal & Hattfjelldal & 65 & 105 & 40 & 16 & 165 \\
\hline
\end{tabular}




\begin{tabular}{lllllll}
\hline Dønna & Solfjellsjøen & 54 & 54 & 0 & 12 & 0 \\
Nesna & Nesna & 58 & 58 & 0 & 18 & 0 \\
Hemnes & Korgen & 42 & 42 & 0 & 38 & 0 \\
Rana & Mo i Rana & 0 & 0 & 0 & 249 & 0 \\
Lurøy & Lurøy & 127 & 127 & 0 & 22 & 0 \\
Træna & Husøy & Amb. boat & Amb. boat & 0 & 3 & 0 \\
Rødøy & Vågaholmen & Amb. boat & Amb. boat & 0 & 6 & 0 \\
Total & & & & & $\epsilon 6,365$ \\
\hline
\end{tabular}

The use of accompanying midwives during transportation was rare (1.1\% of births). During the study period, there were in total 24 cases registered and the total cost was $€ 2,450$. Fifteen of these cases were from the Vefsn municipality (Mosjøen is the centre of this municipality).

Health care savings: The savings consisted of less use of human resources (midwives) in the new model. Based on conservative estimates, from the hospital trust, the numbers of midwives at Mosjøen and Brønnøysund could be reduced from eight and five to a total of three at both locations, when the 24 hour service was closed. The remaining three midwives were necessary for daytime follow-ups of pregnant women and as accompanying midwives during transportation, when necessary. The midwives were also needed in renal replacement therapy. The savings due to reduction in manning was calculated $€ 589,661$.

In total, the new model (two DOGs) may introduce an annual health care saving to the Helgeland hospital trust of $€ 584,346$.

\subsection{Sensitivity Analysis}

To clarify the robustness of the findings, we run a sensitivity analysis (Drummond et al., 2005). Three major variables were identified: 1) The number of midwives dismissed, 2) The tariff of travelling costs, 3) The use of accompanying midwives during transportation. In the sensitivity analysis, we varied the number of midwives dismissed and tariff of transportation costs by $+/-25 \%$. Due to uncertainties concerning the use of accompanying midwives in the new model, we varied the cost of this service by $+/-50 \%$. The only variable having any significant influence on the result was the number of midwives dismissed. The savings varied between $€ 437,981$ and $€ 732,811$. Details are shown in Figure 2 .

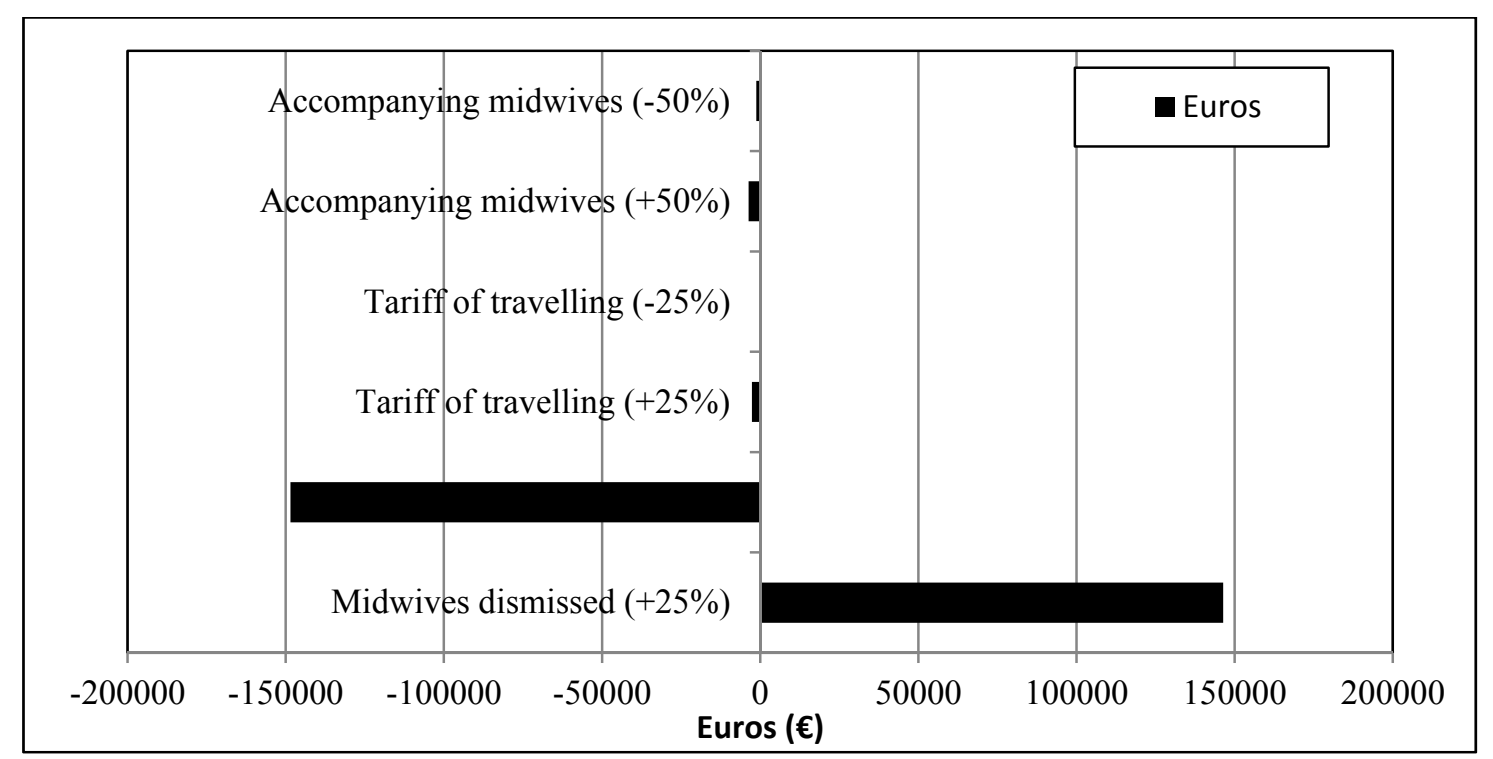

Figure 2. A sensitivity analysis showing the effects of varying costs of accompanying midwives $(+/-50 \%)$, tariff of transportation $(+/-25 \%)$ and number of midwives dismissed $(+/-25 \%) .0=€ 584,346$ 


\section{Discussion}

In this study, we have employed a cost-minimization analysis (CMA) and indicated that the Helgeland hospital trust may save $€ 584,346$ annually by reducing their obstetric care service from four to two delivery units. In total, the mean travel time from home municipality to obstetric care unit will be prolonged by 11 minutes per woman. However, mothers living nearby today's MAMUs (Brønnøysund and Mosjøen) will experience a mean prolonged travelling time of 91 minutes.

There are few studies reported in the literature employing a cost-minimization approach (CMA) in planning the geographical distribution of obstetric facilities or comparing alternatives of care. One such study is from Bangladesh (Khan, 2001). In this study, the authors illustrated the use of a CMA method of planning the geographic distribution of health facilities in order to maximize the social benefits achievable from the investment. They concluded the catchment area defined by the optimal radius minimizes the average social cost of providing emergency obstetric care services in a region. In their populated region, the optimal radius for the 20 regions of Bangladesh was concluded varying from about 6 to $12 \mathrm{~km}$. These figures are far from ours. However, this region do not have access to similar resources of transportation as illustrated in our study. Birnie and colleagues (1997) did also a CMA study. They included 150 consecutive women with high-risk pregnancies. These women entered a randomized controlled trial of in-hospital or domiciliary monitoring. The authors concluded domiciliary monitoring safe and reduced costs by one-half. The technique seemed transferable to other settings. However, again it was commented that local circumstances might hamper its dissemination. A third study employing a CMA in obstetric care was performed in the Netherlands (Vijgen, 2014). This study compared the costs of induction of labor and expectant management in women with preterm prelabor rupture of membranes (PPROM). They concluded in women with pregnancies complicated by PPROM near term, induction of labor did not reduce neonatal sepsis, whereas costs associated with the strategy was probably higher. All these studies illustrates, together with ours, the possible benefits of a CMA analysis in obstetric care, but also shows its limitations with regard to generalizability.

Travel time may influence on quality. In a Dutch study (Ravelli et al, 2011), the impact of travel time by car was analyzed. They revealed a positive relationship between travel time ( $>20$ minutes) and mortality, neonatal mortality within 24 hours and with adverse outcomes. Furthermore, both delivery at 37 week of gestation and 41 weeks of gestation, increased the risk of mortality. The authors recommended their results should be considered in plans for the centralisation of obstetric care in the Netherlands. Japanese researchers (Mine \& Babazono, 2004) have also shown that perinatal mortality was higher in the most rural municipalities compared with urban municipalities. They reported perinatal mortality rates varying from 5.38 to 6.31 , depending on subgroup. Other investigators have revealed diverging findings. In a study from Cumbria in the United Kingdom (Dummer \& Parker, 2004), the median travel time was 12 minutes and maximum 70 minutes. In this study, the risk of infant death did not increase with increasing travel time to hospital, either overall or within specific time periods. Looking at our data (Table 3), only the most populated municipalities have a distance of less than 20 minutes to the delivery unit. A longer distance to travel may increase the risk of birth during transportation. There are about 150 births during transportation in Norway each year (Norwegian Institute of Public Health, 2014, National Centre of Rural Medicine, 2012). During study period (2010-12), there were 489 births during transportation in Norway. We did not have access to explicit data from Helgeland, but Helgeland constitutes one-third of the population of Nordland County. The figure of this county was 35 births during transportation. Consequently the percentage of births during transportation in Nordland County $(0.45 \%)$ was higher than in Norway in general $(0.27 \%)$. Whereas we always try to avoid deliveries during transportation, it should be kept in mind that ambulance personnel are trained to handle such situations and in emergency settings, air ambulance (RW and FW) resources are available within the region. It should also be noted that the women (who will experience a longer distance of travelling in the new model) are the mothers at low risk. In this setting, it is notable that Ravelli and colleagues (2011) did not reveal any effect of travelling time on low risk women at the start of labour and delivering in an outpatient clinic under primary care. This group did also have the lowest mortality rates. In the Helgeland region, those at higher risk are selected for transportation to the DOG/RCOG (based on selection criteria) prior to delivery. They have to stay at nearby family's/friends' home or at the hospital hotel, close to the delivery unit. The fact that the Helgeland region experienced superior absolute values on deaths per 1,000 births (3.7 vs. 3.8) indicates a good maternity care and a working selection system.

We did not include any quality differences between the two alternatives in our model. It has been feared that a reduction in number of units may increase mortality rates. In a Dutch model-based study, they closed 10 out of 99 hospitals in the Netherlands (Poeran et al., 2014). The authors concluded the closure of the smallest ones yielded a suboptimal outcome. In order to get an optimal strategy, they recommended one need to consider all 
positive and negative effects, e.g. organisational heterogeneity of closing and surviving hospitals, differential effects for patient subgroups, increased travel time and financial aspects. In our model, we closed the smallest units. However, this was not based on the 'closure-of-the-smallest-rule', but also on geography, population, infrastructure and travel time. Actually, the model of only two units was run during the summer holiday of 2012. Then, only one DOG and one MAMU was operating simultaneously. In this period, the cost of accompanying midwives during transportation did not increase (personal information from the HH trust). Neither did births during transportation.

Whereas MAMUs in the Helgeland region had about one birth per week, the DOGs had about one birth per day. Consequently, those who deliver at MAMUs may get more attention from the staff. This may be one of the reasons that MAMUs have generally been given higher scores than DOGs in studies analyzing users' satisfaction (unpublished data from the Norwegian knowledge centre). Similarly, an Australian study (Forster, 2016) documented that for women at low risk of medical complications, caseload midwifery increases women's satisfaction with antenatal, intrapartum and postpartum care. Similarly, a study from the Netherlands (Wiegers, 2009) concluded the results of the quality measures indicate that the quality of care as experienced by women is high throughout the care system. However, with regard to the care during labor and birth, the quality of care scores are higher when women know their care provider, when they give birth at home, when they give birth in primary care and when their own midwife assists them. However, the importance of these differences in a longer perspective is minimal as stay during maternity care is generally between 6-48 hours and the mean number of children per woman in Norway is less than two.

In the Helgeland area, accompanying midwives during transportation has been limited to a minimum of cases (5 cases/year). The need has been declining as the communication infrastructure has been upgraded with new/upgraded roads and tunnels shortening distances and removing mountain passages that introduced significant challenges in past years. The situation in the Helgeland region illustrates the tension between improved infrastructure (in terms of new roads, tunnels, bridges, airports, railways) and its possible effects on the cost-effectiveness within health care services. Both politicians and a large proportion of the population want to keep the specialized health care services within a short distance. Arguments vary from keeping jobs within their municipality to safety when in need of emergency care.

In Norway, the number of MAMUs was reduced from 60 to 13 units between 1970 and 2006 (The Norwegian Knowledge Centre for the Health Services, 2006). A similar wave of closure of small maternity services has also been sees in Canada (Grzybowski et al., 2011). This is coincident with the regionalization of health services world-wide and the concomitant challenges in recruiting and retaining providers (Goertzen, 2005). Today's Norwegian trend is clearly towards a more centralised care. The number of births has been steadily declining and this trend is more pronounced in northern Norway (Norum et al., 2013). Whereas Helgeland hospital had 840 births back in 2000, the figure was only 735 in 2012. This trend causes less income to the hospital trusts in terms of DRG points and calls for a centralisation of births to keep hospital budgets in balance. The HH trust's experience during summer 2012 has shown that a centralisation into two delivery units is possible, even when the "birth season occur" (Norum et al., 2014). A centralization of births may make the HH trust more attractive to obstetricians and midwives. Less delivery units may strengthen the group's competence and make it less vulnerable to vacancies and sick leave. As the number of general practitioner surgeons (GP-surgeons) no longer plays an important part in the obstetric care, hospitals have to rely solely on obstetricians (Humber \& Frecker, 2008). Consequently, they will be in need of a larger population to have a sufficient number of patients to achieve a cost-effective service. This has been one of the main arguments of advocates of one Helgeland hospital concentrating all its resources into one hospital. So far, this has been impossible due to today's political situation. However, a further improvement of local infrastructure (roads, tunnels, bridges, railways etc.) may speed up this process.

Our cost-minimum analysis (CMA) did not cause any increased need of human resources. In this setting, midwives dismissed occurred as savings on the hospital's budget. We have based our calculations on data from the hospital trust and the experience during the summer holiday in 2012. We could not detect any indications of raised costs due to accompanying midwives. The longest distances of travel was in the Brønnøysund area. In this setting, it should be kept in mind that Brønnøysund is the home base of two air-ambulances (one RW, one FW). Consequently, in an emergency situation, this region has a superior access to highly competent personnel and effective means of transportation within its municipality.

The Helgeland hospital trust has during several years experienced deficit in their accounting. The lack of surplus has made it difficult to invest in new equipment, upgrade existing buildings and plan for a brand new hospital. In this situation a saving in the obstetric care is welcome. 


\section{Conclusion}

This study has shown that the Helgeland hospital trust may save an amount of almost $€ 600,000$ annually by merging its four obstetric unit into two. It also documents that some women have to cope with a prolonged travelling time when delivery units closed. International research has indicated that long travel distances may influence on perinatal death rate. When planning fewer units, the hospital trust should focus on following national and regional selection criteria. Furthermore, distance to delivery unit should still be kept as an important selection criterion and included in the obstetric manual. When doing perinatal audits, travel time should be included in the inquiries. This to clarify the importance of the variable on quality of care and understand how travel time may influence on the care delivered to women. Finally, we recommend model-based health economic analysis performed, in cooperation with clinicians, when decisions on centralisation of obstetric care is planned.

\section{Acknowledgements}

The authors wish to thank the staff at the Administration of the Helgeland hospital trust for their support, making data available and answering various questions during study period. We are also thankful to the personnel at the library at the UiT-The Arctic University of Norway for their assistance.

\section{Competing Interests Statement}

The authors declare that there is no conflict of interests regarding the publication of this paper.

\section{References}

Birnie, E., Monincx, W. M., Zondervan, H. A., Bossuyt, P. M., \& Bonsel, G. J. (1997). Cost-minimization analysis of domiciliary antenatal fetal monitoring in high-risk pregnancies. Obstet Gynecol, 89(6), 925-929. http://dx.doi.org/10.1016/S0029-7844(97)00150-6

Drummond, M. F., Schulpher, M. J., Torrance, G. W., O’Brien, B. J. \& Stoddart, G. L. (2005). Methods for Economic Evaluation of Health Care Programmes. Oxford, U.K.: Third edition. Oxford University Press.

Dummer, T. J., \& Parker, L. (2004). Hospital accessibility and infant death risk. Arch Dis Child, 89(3), 232-234. http://dx.doi.org/10.1136/adc.2003.030924

Forster, D. A., McLachlan, H. L., Davey, M. A., Biro, M. A., Farrell, T., Gold, L., ... Waldenström, U. (2016). Continuity of care by a primary midwife (caseload midwifery) increases women's satisfaction with antenatal, intrapartum and postpartum care: results from the COSMOS randomised controlled trial. $B M C$ Pregnancy Childbirth, 16(1), 28. http://dx.doi.org/10.1186/s12884-016-0798-y

Goertzen, J. (2005). The four-legged kitchen stool. Recruitment and retention of rural family physicians. Can Fam Physician, 51(9), 1181-1183.

Grzybowski, S., Stoll, K., \& Kornelsen, J. (2011). Distance matters: A population based study examining access to maternity services for rural women. BMC Health Serv Res, 11, 147. http://dx.doi.org/10.1186/1472-6963-11-147

Humber, N., \& Frecker, T. (2008). Delivery models of rural services in British Columbia (1996-2005): Are general practitioner - surgeons still part of the picture? Can J Surg, 51(3), 173-178.

Khan, M. M., Ali, D., Ferdousy, Z., \& Al-Mamun, A. (2001). A cost-minimization approach to planning the geographical distribution of health facilities. Health Policy Plan, 16(3), 264-272. http://dx.doi.org/10.1093/heapol/16.3.264

Mine, Y., \& Babazono, A. (2004). Regional differences in perinatal mortality rates in Japan - an investigation based on vital statistics. Nippon Eiseigaku Zassshi, 59(3), 342-8. http://dx.doi.org/10.1265/jjh.59.342

Ministry of Health and Care Services. (2009). Stortinget, report number 47, 2008-9. The coordination reform. Correct treatment-at the right place-at the correct time. Oslo, Norway: Ministry of Health and Care Services.

National Centre of Rural Medicine. (2012). Projects - births during transportation in Norway. Tromsø, Norway: National Centre of Rural Medicine. Retrieved from http://www.nsdm.no/transportfoedsler_i_norge

Northern Norway Regional Health Authority trust. (2011). Decentralized obstetric care in Helse Nord. Board case no. 31-2011. Bodø, Norway: Northern Norway Regional Health Authority trust.

Norum J., Heyd A., Hjelseth B., Svee T., Mürer F.A., Erlandsen R. \& Vonen B. (2013). Quality of obstetric care in the sparsely populated sub-arctic area of Norway 2009-2011. BMC Pregnancy \& Childbirth, 13, 175-184. http://dx.doi.org/10.1186/1471-2393-13-175 
Norum, J., Heyd, A., \& Svee, T. E. (2014). Most Scandinavians are born during summer time and less Norwegians are born the first quarter of the year: A study comparing Scandinavian birth patterns 2000-2012. Glob J Health Science, 6(4), 163-168. http://dx.doi.org/10.5539/gjhs.v6n4p163

Norwegian Directorate of Health. (2010). A safe maternity care. Quality requirements. Oslo, Norway: Norwegian Directorate of Health.

Norwegian Directorate of Health. (2011). Activity-based financing for 2012. IS1945. Oslo, Norway: Norwegian Directorate of Health.

Norwegian Institute of Public Health. (2014). Medical Birth Registry. Bergen, Norway: Norwegian Institute of Public Health, Medical Birth Registry. http://www.fhi.no/mfr

Norwegian Knowledge Centre for the Health Services. (2006). Report from the Norwegian Knowledge Centre for the Health Services no 16-2006. A systematic overview. Midwife administered maternity units. Oslo, Norway: The Norwegian Knowledge Centre for the Health Services. Retrieved from http://www.kunnskapssenteret.no/publikasjoner/jordmorstyrte-fødestuer

Poeran, J., Borsboom, G. J., de Graaf, J. P., Birnie, E., Steegers, E. A., Mackenbach, J. P., \& Bonsel, G. J. (2014). Does centralisation of acute obstetric care reduce intrapartum and first-week mortality? An empirical study of over 1 million births in the Netherlands. Health Policy, 117(1), 28-38. http://dx.doi.org/10.1016/j.healthpol.2014.03.009

Ravelli, A. C. J., Jager, K. J., de Groot, M. H., Erwich, J. J. H. M., Rijninks-van Direl, G. C., Tromp, M., ... Mol B. W. J. (2011). Travel time from home to hospital and adverse perineal outcomes in women at term in the Netherlands. BJOG, 118(4), 457-465. http://dx.doi.org/10.1111/j.1471-0528.2010.02816.x

Statistics Norway. 2014. Bank of statistics. Oslo, Norway: Statistics Norway. https://www.ssb.no/befolkning

Vijgen, S. M., van der Ham, D. P., Bijlenga, D., van Beek, J. J., Bloemenkamp, K. W., Kwee, A., ... Opmeer, B. C. (2014). Economic analysis comparing induction of labor and expectant management in women with preterm prelabor rupture of membranes between 34 and 37 weeks (PPROMEXIL trial). Acta Obstet Gynecol Scand, 93(4), 374-81. http://dx.doi.org/10.1111/aogs.12329

Wiegers, T. A. (2009). The quality of maternity care services as experienced by women in the Netherlands. BMC Pregnancy Childbirth, 9, 18. http://dx.doi.org/10.1186/1471-2393-9-18

\section{Copyrights}

Copyright for this article is retained by the author(s), with first publication rights granted to the journal.

This is an open-access article distributed under the terms and conditions of the Creative Commons Attribution license (http://creativecommons.org/licenses/by/3.0/). 